\title{
Voice Based Email for Blind
}

\author{
Mullapudi Harshasri' ${ }^{1}$, Manyam Durga Bhavani ${ }^{2}$, and Misra Ravikanth ${ }^{3}$ \\ ${ }^{1,2}$ Students, Department of Computer Science Engineering, Dhanekula Institute of Engineering and Technology, \\ Andhra Pradesh, India \\ ${ }^{3}$ Assistant Professor, Department of Computer Science \& Engineering, Dhanekula Institute of Engineering and Technology, \\ Andhra Pradesh, India
}

Correspondence should be addressed to M. Harshasri: harshasrimullapudi@gmail.com

Copyright ( $) 2021$ Made Mullapudi Harshasri et al. This is an open access article distributed under the Creative Commons Attribution License, which permits unrestricted use, distribution, and reproduction in any medium, provided the original work is properly cited.

\begin{abstract}
Now-a-days internet has become one of the basic aids for day-to-day living. Every human being is widely accessing the knowledge, information and also using for communication through internet. However, blind people face difficulties in accessing these net-based information, also in using any service provided through internet. The advancement in computer based accessible systems has opened up many possibilities for the visually impaired across the worlds in a wide way. Audio based virtual environment like, the screen readers and many voice-based search engines have helped Blind people to access internet applications immensely. We describe the Voice-based mail system architecture that can be used by a Blind person to access e-Mails easily and efficiently. The contribution made by this research has enabled the Blind people to send and receive voice-based e-Mail messages with the help of a computer.
\end{abstract}

KEYWORDS- Text-to-Speech convertor, Speech-toText convertor, Chatbot

\section{INTRODUCTION}

In today's age of communication, the internet is crucial. The internet has become the foundation of today's world. Without the internet, no work can be completed. Email, or electronic mail, is the most vital aspect of daily living. According to a poll, there are around 260 million visually impaired people worldwide. This also implies that these individuals have no knowledge on how to utilize the internet or e-mail, as well as more technological advancements [1]. People with the disability face difficulties with accessing the Internet and the services provided by it. Most of them cannot access and not interested in accessing the services provided by the internet because of the inability and there isn't any other possibility for those people to make use of the services on their own. The solution for this problem is to involve a third person who doesn't have any disabilities but this might not be best way for providing privacy to the user [3]. The proposed system has been designed to overcome the involvement of the third person to send the emails. Our system is developed using Speech-to-Text and Textto-Speech which helps the disabled to send and receive emails on their own without remembering the keyboard shortcuts as well as the location of keys just by using voice commands we can access our email.

\section{EXISTING SYSTEM}

Simple e-mail systems are available in which only voice recognition \& text-to-speech systems are accessible by remembering the keyboard shortcuts to access. The existing voice-based e-mail system has made use of IVR, Speech to text converter, Mouse click event and Screen reader. There will be a small icon of mic on who's clicking the user had to speak and his/her speech will be converted to text format, which the blind people would see and read also, as in references [1][6].

\section{Disadvantages:}

- User have to use mouse connected to the computer and should perform mouse click events to send and receive emails.

- In existing system, they have chosen Web UI as the interface for system which is not easy for the impaired people to use

\section{PROPOSED SYSTEM}

Because using this technology involves visual perception, it is extremely difficult for visually impaired persons to use it. This is because in order to access the internet you would need to know what is written on the screen, which is not possible by blind person. In this proposed system it mainly concentrates on four different types of technologies Speech-to-Text (STT) this module collects the speech given by the user and converts to Text, Textto-Speech (TTS) this converts the response give to system to Speech, Chatbot for making the conversation more sense and for giving responses more like a human and finally, mail communication module for sending and receiving emails. The work flow of proposed system is as shown in figure 1

\section{Advantages:}

- Doesn't need any mouse click events to send and receive emails.

- Purely based on the voice commands given by the user.

- Chatbot is used to make the conversation smooth and more like a human response. 


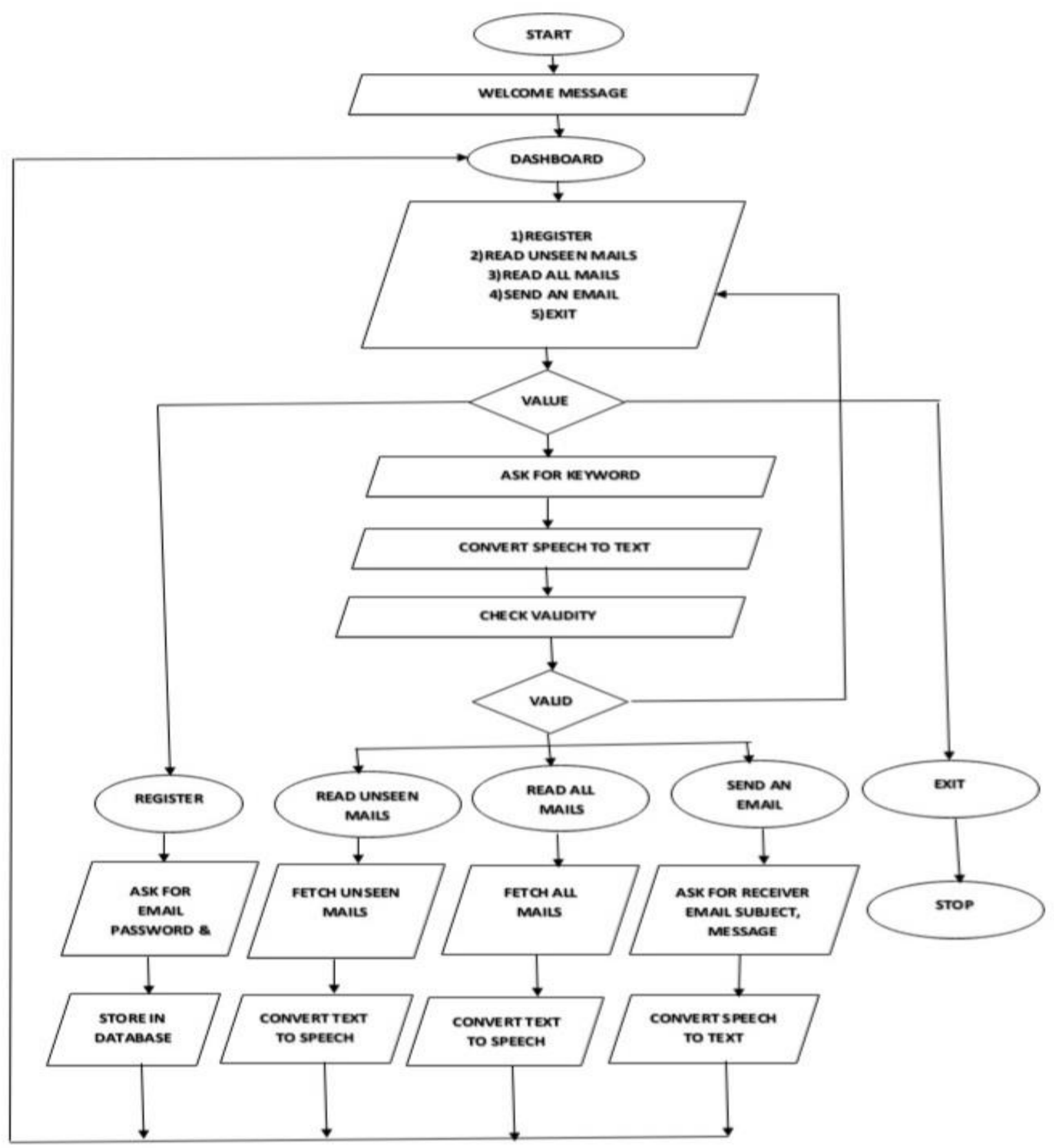

Fig.1: Flow chart of Proposed System

\section{DESIGN}

\section{A. User Interface Design}

Our application user interface is simply a standalone application (Desktop based application) which is very easy to access in a fast way than any other website or app. Now the Stand alone application view is as shown in Figure 2.

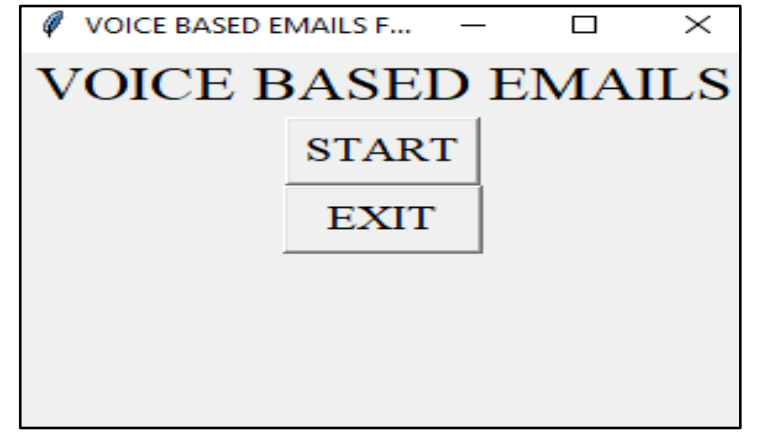

Fig. 2: User interface 


\section{B. Database Design}

Our system maintains a database for user validation. We have created a table which

contains Name, Mail-id, Password and Personal keyword as attributes. These details are stored in database (PhpMyAdmin) for user validation.

\section{System Design}

Our System is voice oriented. When user opens the application, it will give a voice message that application is about to use. The system will say all the option available in this email application such as Send mail, reading unseen Mails, reading all mails, Register and Exist. We have to choose an option among the options available by using voice command. The system work flow is defined as system architecture as shown in figure 3.

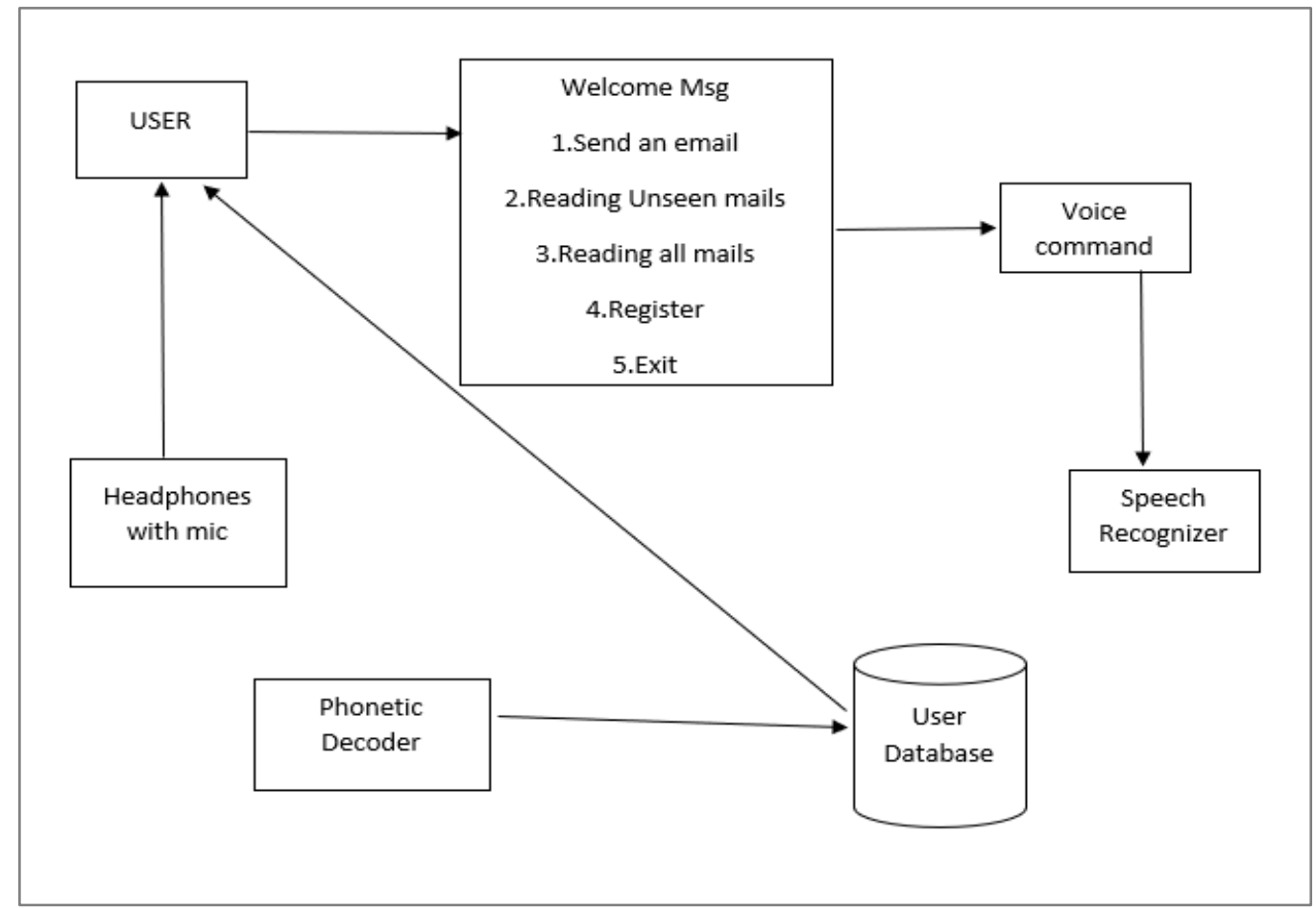

Fig. 3: System architecture

\section{IMPLEMENTATION}

\section{A. Registration}

User has to choose the option Register. We need a trusted second person in order to register because if the blind person pronunciation is not that much clear then the wrong credentials are stored in the database which is not possible to send or read mails in future. For privacy purpose the user has to create a 4-digit keyword which has to be unique the user has to say that keyword in order to access their mail without saying password every time.

The figure 4 shows the user view of registration page

\begin{tabular}{|l|l|l|}
\hline Voice Based Mails & \\
Enter Name & & \\
Enter Email & & \\
Enter Password & & \\
Enter KeyWord & \\
& & \\
& & \\
& & \\
& & \\
& & \\
& & \\
& & \\
& & \\
& & \\
\end{tabular}

Fig. 4: Registration page

\section{B. Send mail}

User has to say the option / send an email as a command. In order to login the user has to say

their personal keyword. Then the chatbot asks the receivers email id, Subject, Message. After the chatbot gives a message "Mail Sent Successfully" by voice.

\section{Reading Unseen mails}

User has to say the option/ Reading All mails as a command. In order to login the user has to say their personal keyword. Then the chatbot read all the unseen mails and asks the user to give reply or not. The user has to YES/NO as an input Command.

\section{Reading All mails}

User has to say the option/ Reading All mails as a command. In order to login the user has to say their personal keyword. Then the chatbot read all the mails and asks the user to move to the next or not. The user has to YES/NO as an input Command. 


\section{RESULT}

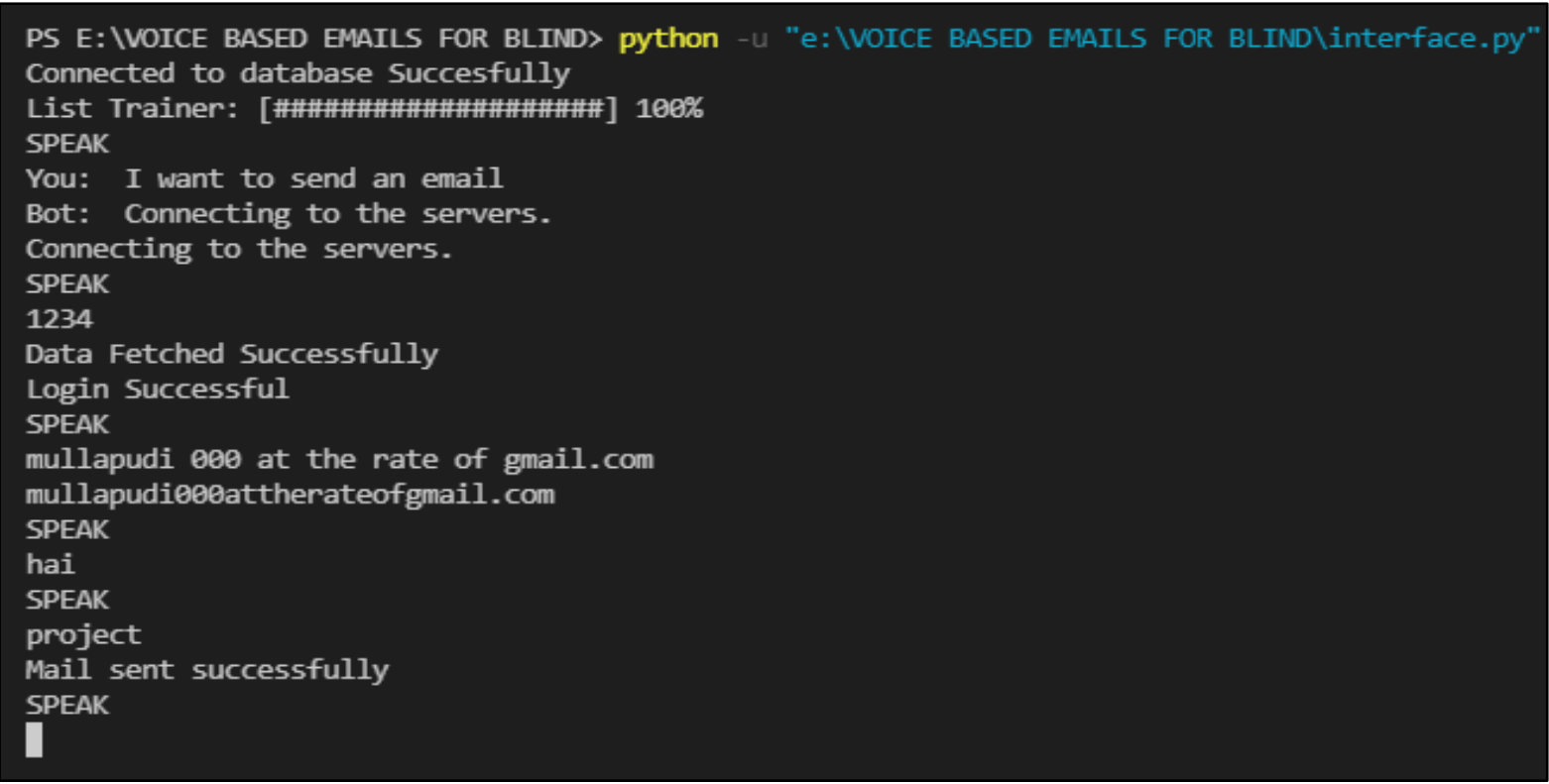

Fig. 5: Testing the model

The figure 5 shows the testing of the module "Send an email".

\section{FUTURE SCOPE}

For people who can see, e-mailing is not a big deal, but for people who are not blessed with gift of vision it postures a key concern because of its intersection with many vocational responsibilities. As a future scope voice could be extended to image attachments and other options such as indentation, fonts etc., that are available with normal E-Mail.

\section{CONCLUSION}

The main objective of the project is to establish email communication based on voice commands for blind people because of their inability to use internet and its functions. We achieved in receiving unseen mails giving senders mail id, subject, message in the form of voice as output. We achieved building text_to_speech, speech_to_text modules and also implemented a chatbot from effective communication between the user and the system, it can not only establish email communication but can also answer the questions asked by the user. We created a registration module for ease of access to user and also providing security and privacy up to some extent.

\section{CONFLICTS OF INTEREST}

The authors declare that they have no conflicts of interest

\section{REFERENCES}

[1] Parkhi Bhardwaj, Gunjan Sethi "Voice Based E-mail System for Visually Impaired: A Review" published in International Research Journal of Engineering and Technology (IRJET) on December $12^{\text {th }}, 2020$.
[2] John Klensin; Ned Freed; Marshall T. Rose; Einar A. Stefferud; Dave Crocker (November 1995). SMTP Service Extensions. IETF. doi:10.17487/RFC1869. RFC 1869.

[3] K. Jayachandran, P. Anbunami: "Voice Based Email for Blind People" published in International Journal of Engineering and Technology in 2018.

[4] Carmel Mary Belinda, Rupavathy.N, Mahalakshmi N R: "Voice based e-mail System for Visually Impaired" published in International Journal of Engineering and Technology in 2018.

[5] Mamatha, A., Jade, V., Saravana, J., Purshotham, A., \& Suhas, A. V. (2020): "Voice Based E-mail System for Visually Impaired" published in International Journal of Research in Engineering, Science and Management.

[6] Belekar A, Sunka S, Bhawar N, \& Bagade S: "Voice Based E-mail for The Visually Impaired" published in International Journal of Computer Applications.

\section{ABOUT THE AUTHORS}

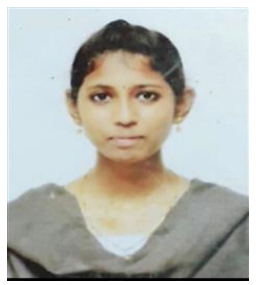

Mullapudi Harshasri, Bachelor of Technology(BTech), Final Year student seeking her degree in Computer Science \& Engineering at Dhanekula Institute of Engineering and Technology, Vijayawada, Andhra Pradesh

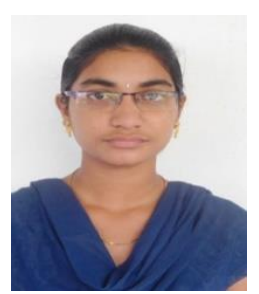

Manyam Durga Bhavani, Bachelor of Technology(BTech), Final Year student seeking her degree in Computer Science \& Engineering at Dhanekula Institute of Engineering and Technology, Vijayawada, Andhra Pradesh 